\title{
Noradrenergic stabilization of heterosynaptic LTP requires activation of Epac in the hippocampus
}

\author{
Nathan J. Brandwein and Peter V. Nguyen \\ Department of Physiology and Institute of Neuroscience and Mental Health, University of Alberta School of Medicine, Edmonton, Alberta \\ T6G 2H7, Canada
}

\begin{abstract}
Beta-adrenergic receptor ( $\beta$-AR) activation by norepinephrine (NE) enhances memory and stabilizes long-term potentiation (LTP), a form of synaptic plasticity believed to underlie some forms of hippocampal memory. LTP can occur at multiple synaptic pathways as a result of strong stimulation to one pathway preceding milder stimulation of an adjacent, independent pathway. Synaptic tagging allows LTP to be transferred, or captured, at heterosynaptic pathways. Previous research has shown that $\beta$-AR activation promotes heterosynaptic LTP by engaging various signaling cascades. In particular, cyclic adenosine monophosphate (cAMP) activates CAMP-dependent protein kinase A (PKA) and guanine nucleotide exchange protein activated by CAMP (Epac), to enhance LTP. Epac activation can occlude subsequent induction of stable homosynaptic LTP after $\beta$-AR activation, but it is unclear whether Epac activation is required for heterosynaptic LTP following pairing of the natural transmitter, NE, with one $100 \mathrm{~Hz}$ train of stimulation ("NE-LTP"). Using electrophysiologic recordings of CAl field excitatory postsynaptic potentials during stimulation of two independent synaptic pathways in murine hippocampal slices, we show that distinct inhibitors of Epac blocked stabilization of homo- and heterosynaptic NE-LTP. PKA inhibition also attenuated heterosynaptic transfer of NE-LTP, but only when a PKA inhibitor was applied during tetanization of a second, heterosynaptic pathway that was not treated with NE. Our data suggest that NE, paired with $100 \mathrm{~Hz}$, activates Epac to stabilize homo- and heterosynaptic LTP. Epac may regulate the production of plasticity-related proteins and subsequent synaptic capture of NE-LTP at a heterosynaptic pathway. Epac activation under these conditions may enable behavioral experiences that engage noradrenergic inputs to hippocampal circuits to be transformed into stable long-term memories.
\end{abstract}

Norepinephrine (NE) is a neuromodulatory transmitter secreted in response to arousal and novelty (Aston-Jones and Bloom 1981; Sara and Segal 1991). Noradrenergic fibers project from the locus coeruleus to innervate the hippocampus, which expresses betaadrenergic receptors ( $\beta$-ARs) that bind NE (Hillman et al. 2005). Activation of $\beta$-ARs by NE engages signaling cascades that facilitate long-term neural plasticity (Stanton and Sarvey 1984; Harley et al. 1996; Katsuki et al. 1997; for review, see Nguyen and Gelinas 2018) and memory formation (Izquierdo et al. 1998; Straube et al. 2003; Lemon et al. 2009; for review, see O'Dell et al. 2015). Activation of $\beta$-ARs in area CA1 of the hippocampus, a brain structure critical for memory formation (Scoville and Milner 1957; Zola-Morgan et al. 1986; Eichenbaum 2000), facilitates activity-dependent increases in synaptic strength (Thomas et al. 1996; Gelinas and Nguyen 2005; for review, see O'Dell et al. 2015).

One type of hippocampal synaptic plasticity is long-term potentiation (LTP) (Bliss and Lømo 1973). LTP is believed to be a cellular mechanism for memory formation in the mammalian brain (Bliss and Collingridge 1993; Bourtchuladze et al. 1994; Ji et al. 2003a; Gelinas and Nguyen 2005; Whitlock et al. 2006; for review, see Martin et al. 2000), and it can be sustained by treating in vitro hippocampal slices with either a $\beta$-AR agonist, isoproterenol (ISO) (Thomas et al. 1996; Katsuki et al. 1997; Gelinas and Nguyen 2005), or with the natural $\beta$-AR ligand, NE (Katsuki et al. 1997; $\mathrm{Hu}$ et al. 2007; Maity et al. 2016; for review, see O'Dell et al. 2015). Furthermore, $\beta$-AR activation by ISO or NE boosts the endurance of LTP by activating signaling kinases to modulate translation initiation and increase the synthesis of specific proteins (Winder

\section{Corresponding author: peter.nguyen@ualberta.ca}

Article is online at http://www.learnmem.org/cgi/doi/10.1101//m.048660.118. et al. 1999; Klann et al. 2004; Gelinas et al. 2007; Maity et al. 2015; for review, see O'Dell et al. 2015). In general, translation is critical for stabilizing LTP (Krug et al. 1984; Costa-Mattioli et al. 2009; Maity et al. 2015).

Heterosynaptic LTP occurs when synaptic activity at one group of synapses initiates cellular mechanisms that elicit synaptic potentiation at a second group of synapses converging on the same postsynaptic neurons. One potential cellular mechanism for heterosynaptic LTP is synaptic tagging (Frey and Morris 1997). According to this model, an LTP-inducing stimulus generates a local synaptic "tag" at one set of tetanized synapses. Tags function to capture plasticity-related proteins (PRPs) that are generated at a different group of synapses that had previously experienced strong stimulation. Normally, applying a modest LTP induction protocol (e.g., one train at $100 \mathrm{~Hz}$ ) to a "homosynaptic" pathway induces decremental potentiation. However, eliciting persistent LTP with stronger stimulation at another convergent pathway will transfer LTP to the weakly stimulated pathway, leading to long-lasting potentiation at both pathways (Frey and Morris 1997; Sajikumar et al. 2007). Importantly, ISO-induced persistent homosynaptic LTP at one pathway can be captured at a second, heterosynaptic pathway (Connor et al. 2011). However, it is unclear whether the natural $\beta$-AR ligand, $\mathrm{NE}$, can facilitate heterosynaptic capture of LTP.

(C) 2019 Brandwein and Nguyen This article is distributed exclusively by Cold Spring Harbor Laboratory Press for the first 12 months after the full-issue publication date (see http://learnmem.cshlp.org/site/misc/terms.xhtml). After 12 months, it is available under a Creative Commons License (AttributionNonCommercial 4.0 International), as described at http://creativecommons. org/licenses/by-nc/4.0/. 
$3^{\prime}, 5^{\prime}$-Cyclic adenosine monophosphate (cAMP) is a key second messenger that is strongly implicated in hippocampal LTP and memory consolidation. Stimulation of cAMP signaling in area CA1 is sufficient to initiate long-lasting synaptic potentiation (Frey et al. 1993). Inhibiting or mutating hippocampal cAMPdependent protein kinase (PKA), which is activated by cAMP, impairs tetanus-induced heterosynaptic LTP (Young et al. 2006) and blocks hippocampal memory consolidation (Abel et al. 1997). ISO-induced heterosynaptic LTP requires PKA activation in murine area CA1 (Connor et al. 2011). Besides PKA, another target of cAMP is guanine exchange protein directly activated by cAMP (Epac). Epacs are expressed in the nervous system (Kawasaki et al. 1998) and they bind cAMP to activate a GTPase, Rap, in a PKAindependent fashion (de Rooij et al. 1998). In area CA1 of murine hippocampal slices, pharmacologic activation of Epac stabilizes homosynaptic LTP independent of PKA and it occludes subsequent expression of tetanus-induced homosynaptic LTP (Gelinas et al. 2008). However, it is unknown whether activation of Epac or PKA is required for stabilization of NE-mediated LTP.

In area CA1 of murine hippocampal slices, pairing bath application of NE with one train of $100 \mathrm{~Hz}$ stimulation elicits longlasting homosynaptic LTP ("NE-LTP"; Maity et al. 2016). In the present study, we characterized the effects of NE on heterosynaptic LTP by using an in vitro, dual synaptic pathway stimulation protocol. In area CA1 of murine hippocampal slices, two independent populations of synapses contacting the same postsynaptic cells were monitored to assess the effects of prior induction of homosynaptic NE-LTP at one pathway (S1) on the subsequent induction of heterosynaptic LTP at a second pathway (S2). We asked two questions: First, can NE paired with $100 \mathrm{~Hz}$ stimulation in S1 elicit stable heterosynaptic LTP in S2? Second, if NE-LTP can be produced, does its stabilization require activation of Epac? Using specific pharmacological inhibitors of Epac and PKA, we show that long-lasting NE-LTP occurred mostly through a PKA-independent mechanism. Stabilization of homosynaptic and heterosynaptic NE-LTP required Epac activation during $100 \mathrm{~Hz}$ stimulation at S1 and S2. In contrast, PKA activation was required for heterosynaptic transfer of NE-LTP only during $100 \mathrm{~Hz}$ stimulation at S2, but not during paired $100 \mathrm{~Hz}$ and NE application at S1. Our results reveal a novel mechanistic dichotomy for heterosynaptic NE-LTP stabilization, involving possibly distinct contributions from Epac and PKA.

\section{Results}

\section{Norepinephrine stabilizes heterosynaptic LTP}

NE binds to $\beta$-ARs to facilitate potentiation at excitatory hippocampal synapses (Stanton and Sarvey 1984; Harley et al. 1996; Katsuki et al. 1997). When applied before, or during, a single $100 \mathrm{~Hz}$ tetanus that normally elicits decremental LTP, NE enables the expression of long-lasting homosynaptic LTP in area CA1 of mouse hippocampal slices ("NE-LTP": Maity et al. 2015, 2016). Pairing ISO, a $\beta$-AR agonist, with one train of $100 \mathrm{~Hz}$ (Gelinas and Nguyen 2005; Gelinas et al. 2007) or with low-frequency stimulation (Thomas et al. 1996) also induces long-lasting homosynaptic LTP ("ISO-LTP"). ISO-LTP can be evoked at a second heterosynaptic input in mouse area CA1, thus implicating a role for $\beta$-ARs in modulating synaptic tagging and capture of PRPs at these synapses (Connor et al. 2011), processes believed to enable synapse-specific transfer of LTP between activated pathways (Frey and Morris 1997). However, it is unclear whether NE, the natural ligand of adrenoreceptors, can stabilize heterosynaptic LTP in area CA1.

To test this idea, we first needed to establish the effects of one train of $100 \mathrm{~Hz}$ on field excitatory postsynaptic potentials (fEPSPs) in the Schaeffer collateral pathway of CA1. Upon stimulation of S1 (the homosynaptic pathway) and S2 (the heterosynaptic pathway) 30 min apart, LTP at S1 and S2 was not sustained (Fig. 1A,C $100 \mathrm{~Hz}$ columns). This finding is corroborated by previous research, in which a paired stimulation protocol, without any applied transmitter agonist, was insufficient for inducing longlasting LTP (Connor et al. 2011). Thus, one train of $100 \mathrm{~Hz}$ applied to separate pathways did not elicit enduring LTP. Our results show that $\mathrm{S} 1$, having received only a single tetanus, did not promote subsequent capture of LTP by tags set later, at $\mathrm{S} 2$.

To determine if NE can stabilize heterosynaptic LTP, we treated slices with NE for $10 \mathrm{~min}$ prior to one train of $100 \mathrm{~Hz}$ at S1. NE
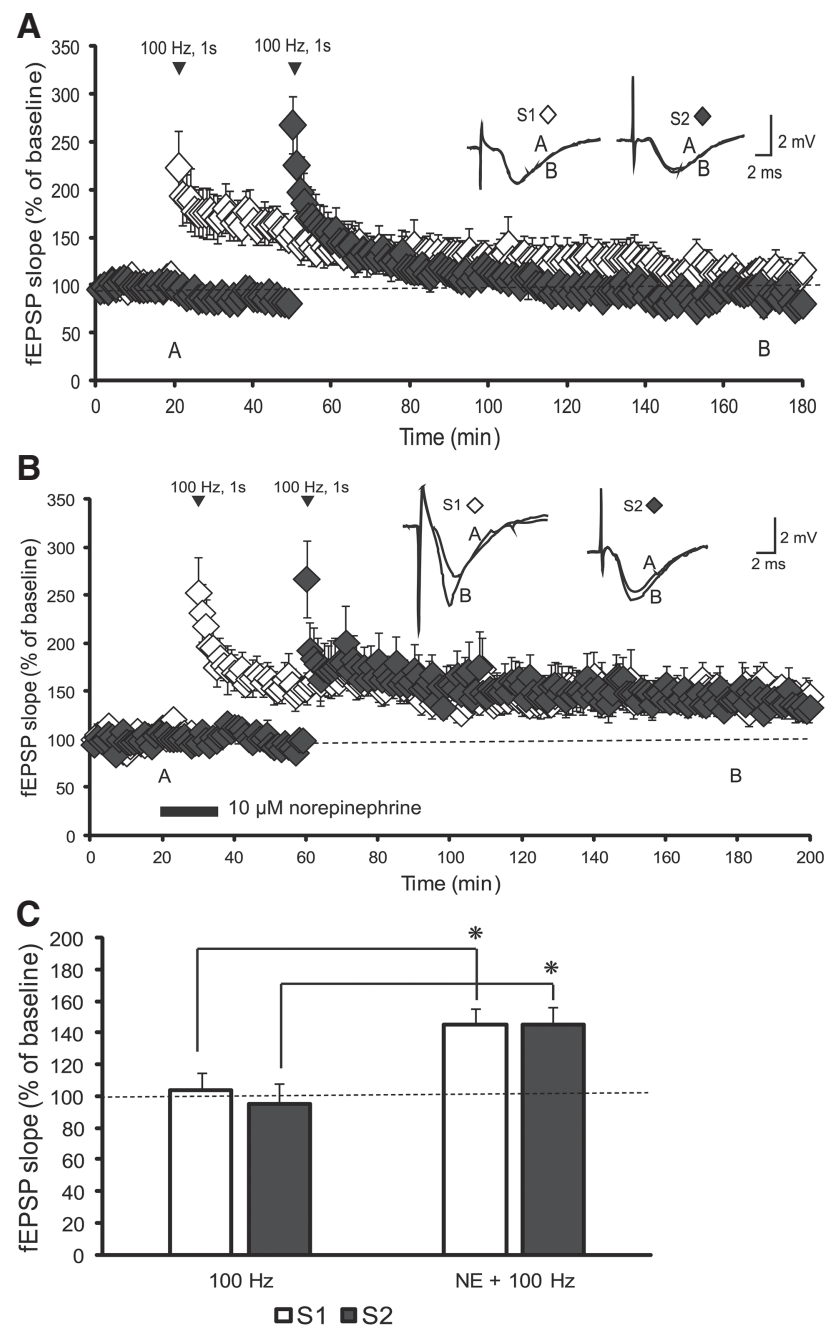

Figure 1. NE facilitates the expression of heterosynaptic LTP. (A) Stimulation (one train of $100 \mathrm{~Hz}$ for $1 \mathrm{sec}$ ) of the homosynaptic pathway (S1; open symbols) induced transient $(<1 \mathrm{~h})$ LTP which failed to promote heterosynaptic LTP upon administering an identical stimulus to a second synaptic pathway (S2; filled symbols) 30 min later $(n=7)$. Stimulation at $100 \mathrm{~Hz}$ alone did not persistently strengthen synapses, as fEPSP slopes at $\mathrm{S} 1$ and $\mathrm{S} 2$ returned to baseline (within $1 \mathrm{~h}$ ). (B) NE application along with $100 \mathrm{~Hz}$ produced persistent homosynaptic LTP in S1 (NE-LTP) that was subsequently captured by $100 \mathrm{~Hz}$ stimulation alone at S2 $(n=6)$. Representative fEPSP traces were sampled 20 min after commencement of baseline recordings and 120 and $90 \mathrm{~min}$ after $100 \mathrm{~Hz}$ stimulation at S1 and S2, respectively. (C) Summary histogram comparing mean fEPSP slopes obtained 150 min after $100 \mathrm{~Hz}$ at S1 (white bars) and $120 \mathrm{~min}$ after $100 \mathrm{~Hz}$ at S2 (gray bars). $\left(^{*}\right)$ Specifies statistical significance $(P<0.05)$ between treatment groups. Results in $C$ denote means \pm SEM. 
continued to perfuse the slices for $5 \mathrm{~min}$ post- $100 \mathrm{~Hz}$ before washout. This protocol, but without NE, was administered to S2 $30 \mathrm{~min}$ after $S 1$ stimulation (Fig. 1B). Student's $t$-test comparisons between control- and NE-treated slices revealed significant differences in the stabilization of LTP, both homosynaptically $(P<0.05$; mean fEPSP slope in NE-treated slices was $145 \pm 10 \%$ of baseline, which was significantly elevated relative to control slices, $104 \pm 11 \%$ of baseline) and heterosynaptically $(P<0.05$; mean fEPSP slope was $145 \pm 11 \%$ in NE-treated slices versus $95 \pm 13 \%$ in controls; Fig. $1 \mathrm{C}$ "NE $+100 \mathrm{~Hz}$ "). Thus, NE-LTP generated at one synaptic pathway leads to long-lasting LTP at a second pathway.

\section{Stabilization of heterosynaptic NE-LTP does not require PKA activation}

Previous studies have revealed that PKA, a downstream target of $\beta$-AR activation, is a key signaling effector for synaptic plasticity and memory consolidation (Abel et al. 1997; Nayak et al. 1998; Duffy et al. 2001; Nguyen and Woo 2003; Woo et al. 2003; Abel and Nguyen 2008). A role for PKA has also been implicated in $\beta$-AR-induced LTP (Thomas et al. 1996) and in synaptic tagging during tetanus-induced late-LTP (Young et al. 2006; Connor et al. 2011). To determine if PKA activation is required for heterosynaptic NE-LTP, we applied an NE-LTP protocol to S1, consisting of one train of $100 \mathrm{~Hz}$ overlapping with bath application of NE in the presence of PKA inhibitors, KT5720 (KT) or PKI. Each inhibitor was bath-applied for $30 \mathrm{~min}$ and washed out prior to stimulation of S2 30 min after S1 stimulation. Addition of PKI (Fig. 2B; mean fEPSP slope was $142 \pm 14 \%$ of baseline) or KT (Fig. 2C; mean fEPSP slope was $167 \pm 18 \%$ of baseline) during $100 \mathrm{~Hz}$ at S1 failed to inhibit homosynaptic NE-LTP at S1 relative to inhibitor-free controls (Fig. 2A; mean fEPSP slope from controls was $151 \pm 10 \%$ of baseline). Furthermore, neither KT nor PKI significantly impaired the endurance of heterosynaptic NE-LTP at S2 (Fig. 2B,C, mean slopes in S2 were: KT $150 \pm 14 \%$ of baseline, PKI $139 \pm 9 \%$ of baseline), as compared to controls (Fig. 2A).

When KT application was shifted to overlap with $100 \mathrm{~Hz}$ at S2 (Fig. 2D), the heterosynaptic pathway experienced decremental
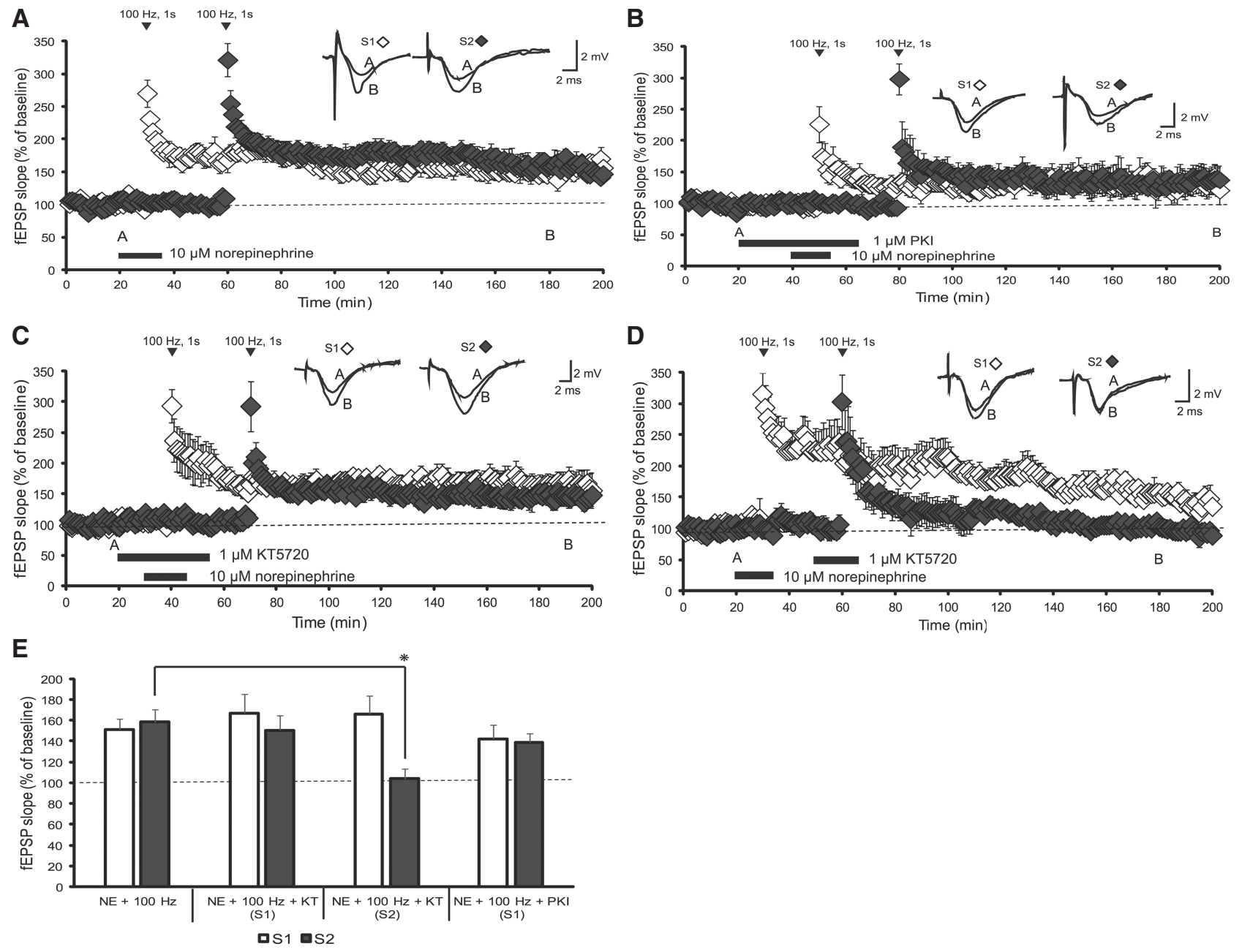

Figure 2. PKA activation is not required for homosynaptic NE-LTP but is required during $100 \mathrm{~Hz}$ stimulation at a heterosynaptic pathway for transfer of stable NE-LTP. (A) Both homosynaptic (open symbols) and heterosynaptic (filled symbols) NE-LTP were persistently expressed following coincident application of NE overlapping with $100 \mathrm{~Hz}$ stimulation to $S 1(n=6)$. When overlapped with NE at S1, the PKA inhibitors, $(B)$ protein kinase A inhibitor peptide (PKI; $n=5)$, and (C) KT5720 (KT; $n=7)$ did not impair homosynaptic or heterosynaptic LTP. (D) Shifting KT application to overlap with 100 $\mathrm{Hz}$ at S2 induced decremental heterosynaptic LTP $(n=6)$. Representative traces were sampled 20 min after commencement of baseline recordings and 120 and $90 \mathrm{~min}$ after $100 \mathrm{~Hz}$ at S1 and S2, respectively. (E) Summary histogram comparing mean fEPSP slopes obtained $150 \mathrm{~min}$ after $100 \mathrm{~Hz}$ at $\mathrm{S} 1$ (white bars) and $120 \mathrm{~min}$ after $100 \mathrm{~Hz}$ at S2 (gray bars). (*) Specifies statistical significance $(P<0.05)$ between treatment groups. Results in $E$ denote means \pm SEM. 
LTP, whereas S1 (which received prior $100 \mathrm{~Hz}+\mathrm{NE}$ ) successfully expressed NE-LTP (mean fEPSP slope was $166 \pm 18 \%$ of baseline at S1 compared to controls and $104 \pm 10 \%$ of baseline at S2). An ANOVA comparing fEPSP slopes of both PKA inhibitor treatments showed no significant differences between groups at $\mathrm{S} 1\left(F_{(3,21)}=\right.$ 0.53 ; $P>0.05)$; however, there was a difference at S2 $\left(F_{(3,21)}=\right.$ 3.91; $P<0.05$ ) (Fig. 2E). A subsequent Tukey-Kramer post-hoc test revealed that KT, when shifted to overlap with $100 \mathrm{~Hz}$ at S2, prevented heterosynaptic transfer of NE-LTP to S2 $(P<0.001)$. Thus, PKA inhibition failed to impair the stability of homo- and heterosynaptic LTP when applied during NE application at S1. In contrast, PKA inhibition during S2 (100 Hz alone) disrupted heterosynaptic transfer of NE-LTP to those "tagged" synapses. In our previous study (Maity et al. 2015), it was shown that $\mathrm{NE}+100 \mathrm{~Hz}$ boosted translation of specific mRNAs (i.e., synthesis of PRPs) during homosynaptic NE-LTP. Taken together with our present data, we conclude that PKA activation is not required for synthesis of PRPs triggered by $100 \mathrm{~Hz}+\mathrm{NE}$ treatment at S1.

\section{Inhibiting Epac prevents expression of NE-LTP at tagged synapses}

A second signaling molecule which cAMP directly activates is Epac. Several findings have implicated Epac activation in hippocampal memory and hippocampal LTP. For example, cAMP signaling modulates memory consolidation through Epac, independent of PKA (Ma et al. 2009). Furthermore, pharmacologic activation of Epac strengthens hippocampal synapses by inducing translationdependent potentiation, which in turn, occluded subsequent induction of long-lasting ISO-LTP (Gelinas et al. 2008). However, the roles of Epac activation in heterosynaptic NE-LTP remain undefined. Particularly, it is unknown whether inhibition of Epac can affect heterosynaptic NE-LTP at hippocampal synapses.

To probe the roles of Epac activation on heterosynaptic NE-LTP, we first established that heterosynaptic NE-LTP could be reliably produced by S2 $100 \mathrm{~Hz}$, given $30 \mathrm{~min}$ after $\mathrm{S} 1100 \mathrm{~Hz}$ in the presence of NE. Mean fEPSP slopes of control slices (treated with NE at S1) were $142 \pm 6 \%$ of baseline and $162 \pm 11 \%$ of baseline at $\mathrm{S} 1$ and S2, respectively (Fig. 3A). We then applied NE $+100 \mathrm{~Hz}$ in the presence of an Epac inhibitor, brefeldin A (BFA). This treatment significantly impaired the stabilities of homosynaptic (Fig. 3B; mean fEPSP slope for S1 was $96 \pm 5 \%$ of baseline) and heterosynaptic NE-LTP (mean fEPSP slope for S2 was $101 \pm 7 \%$ of baseline). We also applied a more specific blocker of Epac, ESI-09 (ESI); this also significantly suppressed homosynaptic and heterosynaptic NE-LTP stability (Fig. 3C; mean fEPSP slopes were $103 \pm$ $6 \%$ of baseline at $\mathrm{S} 1$ and $105 \pm 7 \%$ at S2). Shifting the time of application of BFA, to overlap with $100 \mathrm{~Hz}$ at S2, prevented heterosynaptic transfer of NE-LTP from S1: only the homosynaptic (S1) pathway remained potentiated throughout the recording period (Fig. 3D; mean fEPSP slopes were $129 \pm 4 \%$ of baseline at S1 compared to controls and $91 \pm 10 \%$ of baseline at S2 compared to controls). ESI applied during S2 yielded similar results (Fig 3E; average fEPSP slopes were $142 \pm 20 \%$ at $\mathrm{S} 1$ and $88 \pm 2 \%$ at S2).

An ANOVA was performed to compare differences among pharmacological treatments and a control group. The test identified significant differences between groups homosynaptically $\left(F_{(4,23)}=4.10 ; P<0.05\right)$ and heterosynaptically $\left(F_{(4,23)}=14.07 ; P<\right.$ 0.001) (Fig. 3F). A subsequent Tukey-Kramer post-hoc test revealed that ESI and BFA prevented stabilization of homosynaptic (BFA: $P<$ 0.05; ESI: $P<0.05$ ) and heterosynaptic (BFA: $P<0.001$; ESI: $P<$ $0.001)$ NE-LTP. Additionally, relative to control slices treated only with NE and $100 \mathrm{~Hz}$, applying ESI or BFA during S2 $100 \mathrm{~Hz}$ impaired heterosynaptic, but not homosynaptic, LTP stabilization (BFA: $P<0.001$; ESI: $P<0.001)$. Taken together, our data suggest that activation of Epac, but not of PKA, is required for production of plasticity-related components (proteins?) needed for heterosynaptic transfer of NE-LTP. In contrast, heterosynaptic transfer of NE-LTP to tagged synapses (S2) depends on the activation of Epac during S1 and S2 stimulation, and on PKA activation during S2 stimulation.

\section{Discussion}

NE promotes the formation, retrieval, and retention of hippocampus-dependent spatial and contextual memories, through activation of $\beta$-ARs (Sara et al. 1999; Ji et al. 2003a,b; Murchison et al. 2004). Additionally, $\beta$-ARs modulate hippocampal LTP through the activation of signaling mechanisms that include glutamatergic AMPA receptors, PKA, Epac, ERK, and translation initiation (for review, see O'Dell et al. 2015). Epac has been implicated in distinct forms of synaptic plasticity, including hippocampal homosynaptic LTP (Gelinas et al. 2008; Yang et al. 2012) and cerebellar homosynaptic LTP linked to motor learning (Gutierrez-Castellanos et al. 2017). However, to date, no study has probed the roles of Epac activation in heterosynaptic LTP.

The present study explored the roles of Epac in NE-mediated heterosynaptic plasticity in area CA1 of murine hippocampal slices. Unlike previous studies using the synthetic $\beta$-AR agonist, ISO, we have used here the physiological $\beta$-AR ligand, NE. We found that NE, when paired with one train of $100 \mathrm{~Hz}$ stimulation, facilitated stabilization of heterosynaptic LTP. Our findings are consistent with previous research that used ISO: Connor et al. (2011) found that ISO paired with one train of $100 \mathrm{~Hz}$ at S1 enabled subsequent capture of long-lasting LTP at S2. Interestingly, $5 \mathrm{~Hz}$ stimulation for $10 \mathrm{sec}$ was used at S2 (Connor et al. 2011), and heterosynaptic LTP required activation of $\beta$-ARs, as it was blocked by a $\beta$-AR antagonist (Connor et al. 2011). Qian et al. (2012) showed that prolonged $5 \mathrm{~Hz}$ stimulation in mouse CA1 in the presence of ISO elicited homosynaptic LTP that required activation of $\beta-2$, but not $\beta-1$, adrenergic receptors. Our previous research has shown that homosynaptic NE-LTP after $100 \mathrm{~Hz}$ stimulation in CA1 was dependent on activation of $\beta-1$ and $\beta-2$ receptors, but did not require activation of $\alpha$-ARs (Maity et al. 2016). Thus, the collective findings show that activation of $\beta$-ARs, either with ISO or with the natural transmitter NE (the present study), gates the stabilization of longlasting synaptic potentiation when paired with low- or highfrequency stimulation.

Our data reveal a novel mechanistic dichotomy in the roles of PKA and Epac during heterosynaptic NE-LTP. We found that activation of Epac during S1 and S2 was required for homo- and heterosynaptic NE-LTP. In contrast, PKA activation was required only during $100 \mathrm{~Hz}$ stimulation at S2 (without applied NE at S2) for heterosynaptic capture of NE-LTP. These results are concordant with our earlier studies (Connor et al. 2011) in which a PKA inhibitor (PKI) applied during S1 tetanization (with ISO applied) had no effect on homo- or heterosynaptic ISO-LTP, but blocked heterosynaptic capture of ISO-LTP when it was applied during S2 stimulation at $5 \mathrm{~Hz}$. Thus, PKA activation appears to be critical for synaptic tagging/capture at $\mathrm{S} 2$, and not for triggering the synthesis of PRPs during S1 tetanization paired with $\beta$-AR activation. Young et al. (2006) provided data from mouse CA1, using a strong multitrain tetanization protocol without $\beta$-AR activators to elicit homosynaptic late-LTP, to support the notion that PKA activation is needed for synaptic tagging (see also Park et al. 2014, for a presynaptic role of PKA in tagging during homosynaptic LTP). Connor et al. (2011) showed that protein synthesis during S2 tetanization $(5 \mathrm{~Hz}, 10 \mathrm{sec})$ was not needed for heterosynaptic capture of ISO-LTP; such synthesis was shown instead to be required during S1 tetanization paired with ISO. It is noteworthy that generation 


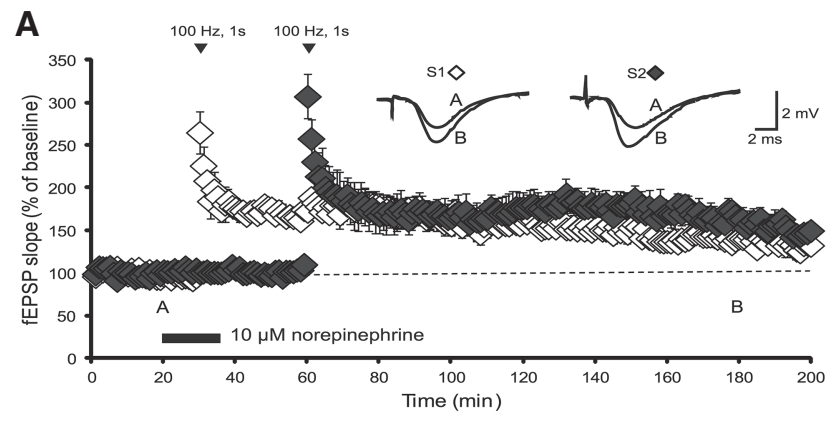

B
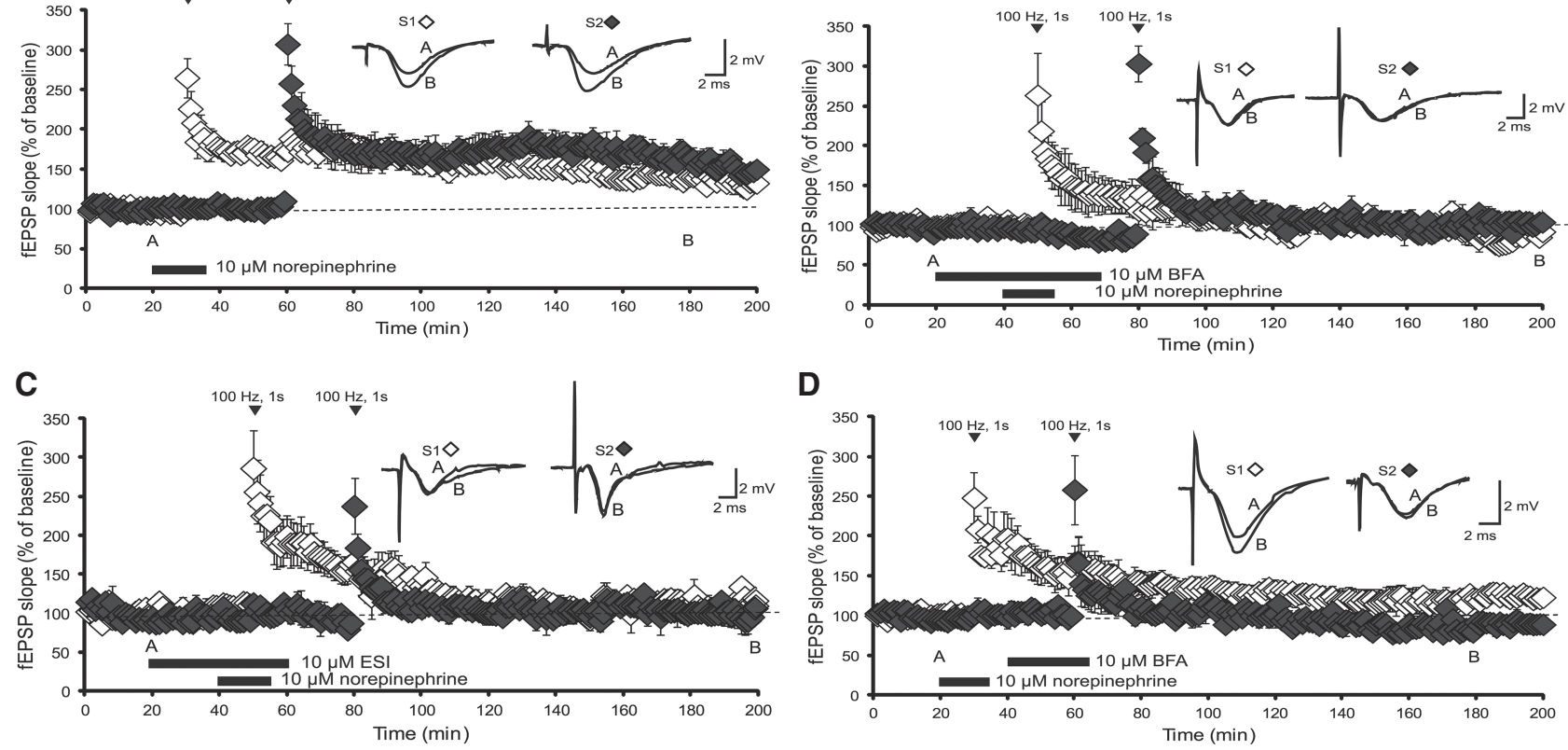

D
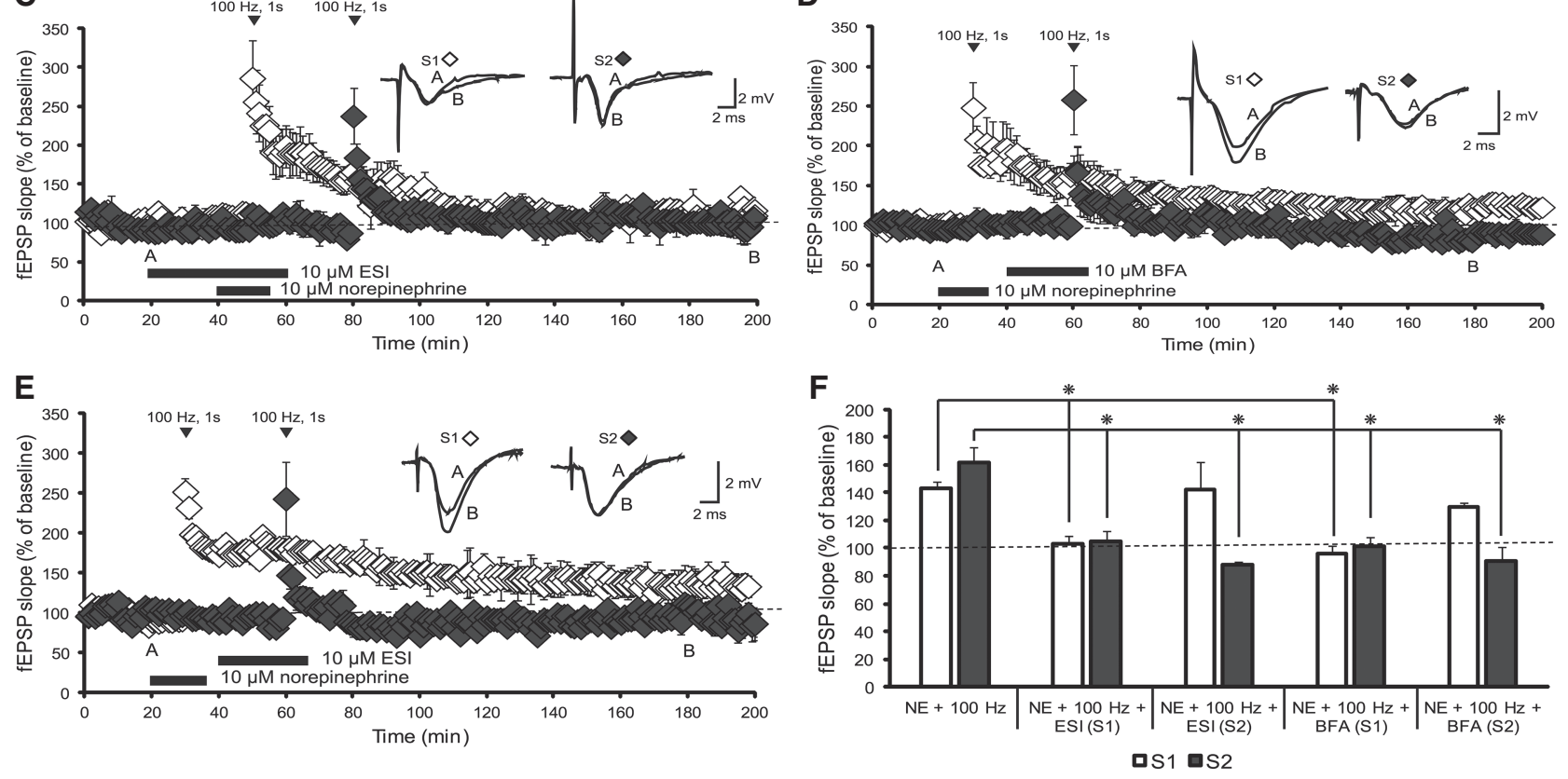

Figure 3. Epac activation is required for heterosynaptic transfer of NE-mediated LTP. (A) NE-LTP was elicited at S1 (open symbols) and subsequently captured at a second pathway (filled symbols) $(n=6)$. Treating hippocampal slices with the Epac inhibitors (B) brefeldin A (BFA) or (C) ESI-09 (ESI), as $S 1$ received $100 \mathrm{~Hz}$ stimulation, reduced homosynaptic LTP stabilization in both pathways $(n=5)$. Delaying application of $(D)$ BFA or $(E)$ ESI to overlap with $100 \mathrm{~Hz}$ at S2, with $100 \mathrm{~Hz}$ and NE administered earlier to S1, prevented heterosynaptic transfer of NE-LTP $(n=6)$. Note that neither BFA nor ESI disrupted LTP maintenance at S1 when applied during $100 \mathrm{~Hz}$ at S2 (open symbols for S1, in D and E). Representative traces were sampled 20 min after commencement of baseline recordings and 120 and $90 \mathrm{~min}$ after $100 \mathrm{~Hz}$ at S1 and S2, respectively. ( $F$ ) Summary histogram comparing average fEPSP slopes obtained $150 \mathrm{~min}$ after $100 \mathrm{~Hz}$ at S1 (white bars) and $120 \mathrm{~min}$ after $100 \mathrm{~Hz}$ at S2 (gray bars). ${ }^{*}$ specifies statistical significance $(P<0.05)$ between treatment groups. Results in $F$ denote means \pm SEM.

of local synaptic tags does not require protein synthesis (Frey and Morris 1997). However, the process of local translation may serve as a tag, since its action allows for the generation of spatially restricted proteins that can modify active synapses to stabilize LTP. In general, the role of PKA may be limited to establishing synaptic tags (to mark activated synapses) following application of relatively modest stimulation (i.e., 1 train of $100 \mathrm{~Hz}$ ) (Barco et al. 2002; Young et al. 2006). During heterosynaptic NE-LTP, PKA may mediate synaptic tagging (and/or subsequent capture of PRPs) at a heterosynaptic pathway after prior NE-LTP induction at a distinct pathway that triggers synthesis of PRPs. PKA's role seems less strongly linked to initiation of translation at S1 during paired application of NE and $100 \mathrm{~Hz}$ tetanization there. PKA itself may be a tag, since its local anchoring at hippocampal synapses plays critical roles in mediating homosynaptic LTP (Nie et al. 2007). Further research is needed to identify proteins phosphorylated by PKA during heterosynaptic NE-LTP.

Our present experiments highlight possible dual roles for Epac activation: recruitment of translation during $S 1$ tetanization paired with NE, and subsequent capture of NE-LTP at S2. Occlusion experiments have demonstrated that ISO-LTP and Epac-induced potentiation (evoked by applying an Epac agonist) share similar underlying mechanisms: the latter occluded subsequent ISO-LTP (Gelinas et al. 2008). Pharmacologic activation of Epac increases hippocampal expression of phosphorylated extracellular signalregulated protein kinase (ERK) (Gelinas et al. 2008), a key regulator of translation-dependent $\beta$-AR LTP (Gelinas et al. 2007; Connor et al. 2011). Phosphorylated ERK is a prime modulator of translation initiation in eukaryotic cells (for reviews, see Klann et al. 2004; Kelleher et al. 2008; Costa-Mattioli et al. 2009). Thus, one key role for Epac activation during NE-LTP may be recruitment of translation initiation, in conjunction with $\mathrm{NE}$, which was paired with $100 \mathrm{~Hz}$ at S1. It is likely that Epac is assisting other factors in mediating translation recruitment. Either NE, or $100 \mathrm{~Hz}$, alone is not enough to significantly boost translation in mouse CA1 (Maity et al. 2015). However, both stimuli applied together (NE + $100 \mathrm{~Hz}$ ) can significantly boost the synthesis of specific proteins in murine CA1, concomitant with stabilization of homosynaptic 
NE-LTP (Maity et al. 2015). We speculate that Epac activation may be required during this pairing in order to link downstream engagement of the ERK pathway with subsequent translation regulation needed for production of PRPs that are subsequently captured by S2. Indeed, inhibition of Epac activation during S2 tetanization in our present study prevented heterosynaptic capture of NE-LTP that was consolidated earlier at S1. Additionally, we emphasize that Epac activation by NE paired with $100 \mathrm{~Hz}$ at S1 is required, but not sufficient, for capture of NE-LTP at S2. In support of this, we showed that PKA activation was also required at S2 for heterosynaptic capture.

Additional support for the general notion that cAMP-mediated signaling is critical for the synthesis of PRPs comes from studies of synaptic tagging and LTP following rolipram-induced synaptic potentiation. By boosting cAMP levels in the hippocampus, rolipram converted unstable LTP to resilient LTP that required translation in rat hippocampal slices (Navakkode et al. 2004). Further research is needed to probe the exact actions of Epac during heterosynaptic NE-LTP. Can Epac act as a local tag, possibly by being localized at active synapses? There is a paucity of evidence to directly show Epac anchoring at hippocampal synapses, although there are data supporting a role for a PKA anchoring protein, AKAP150, in coordinating Epac-mediated phosphorylation (Nijholt et al. 2008). Are other signaling kinases (besides ERK) recruited by Epac activation to engage translation? Characterizing Epac's compartmentalization will be critical for ascertaining how Epac tightly regulates proteins in various pathways. Are the PRPs specific for NE-associated plasticity, or do they belong to a generic class of proteins that can be recruited by multiple neuromodulatory transmitters? There is evidence hinting at the possible existence of distinct tags during different types of synaptic modifications (e.g., LTP and LTD: Sajikumar and Frey 2004). However, it is still unclear whether different neuromodulators can engage distinct PRPs during heterosynaptic plasticity.

From a biochemical-behavioral perspective, it is known that concentrations of NE (and other monoamines such as dopamine and serotonin) in the rodent hippocampus can be increased by strong electrical stimulation that initiates long-lasting potentiation (Neugebauer et al. 2009). Such sensitivity of the levels of key neuromodulatory transmitters to the pattern of synaptic stimulation may influence processing of behavioral events during associative learning. The main source of NE in the brain, the locus coeruleus, may act cooperatively with other brain structures (e.g., the dopaminergic ventral tegmental area) to control the generation of behavioral tags (analogous to synaptic tags) triggered during learning. These "learning tags" may signal where a memory is stored, whereas protein synthesis, gated by $\beta$-AR activation through NE, would allow memories to be consolidated in distinct brain circuits (Moncada 2017). It is known that $\beta$-AR activation is needed for triggering PRP synthesis during behavioral tagging; PKA and calcium/ calmodulin-dependent protein kinase II (CaMKII) are also needed for setting the learning tags (Moncada et al. 2011). It is unclear whether Epac activation is needed for behavioral tagging and subsequent memory consolidation. Nonetheless, the currently sparse literature on Epac and memory processing supports the notion that Epac has key roles in memory dynamics. Epac activation can modulate associative odor memories in rat pups (Grimes et al. 2015), and Epac signaling is critical for hippocampal memory retrieval (Ouyang et al. 2008; Ostroveanu et al. 2010). Conversely, Epac activation in the amygdala impeded cocaine-induced memory reconsolidation (Wan et al. 2014). Epac expression is dysregulated during Alzheimer's disease (AD; McPhee et al. 2005), but the causal link between Epac and memory dysfunction during $\mathrm{AD}$ remains unclear. Insights into the dynamics of Epac in memory-impaired brains could provide a model for noradrenergic signaling during memory processing. Identifying the molecular substrates of Epac and noradrenergic modulation (i.e., NE) will shed light on how cAMP signaling mechanisms, in general, modulate memory consolidation and enable the persistence of associative long-term memories.

\section{Materials and Methods}

\section{Animals}

Male C57BL/6 mice (Charles River Laboratories, Canada) were used for all experiments. Mice (aged 7-12 wk) were fed ad libitum and housed at the University of Alberta in accordance with Canadian Council on Animal Care (CCAC) guidelines. All reported data were obtained from in vitro hippocampal slices. Proper procedures were taken to minimize animal pain and suffering, as approved by the University of Alberta's Heath Sciences Laboratory Animal Services ethics committee.

\section{Hippocampal slice preparation}

Following cervical dislocation and decapitation, the intact mouse brain was removed and placed in ice-cold artificial cerebrospinal fluid (aCSF). Both hippocampi were extracted and sliced transversely (at $400 \mu \mathrm{m}$ thickness) using a tissue chopper. Slices were transferred to an interface chamber (Fine Science Tools, Canada), where they recovered for $\sim 90 \mathrm{~min}$ at $30^{\circ} \mathrm{C}$ and aerated with carbogen $\left(95 \% \mathrm{O}_{2} / 5 \% \mathrm{CO}_{2}\right)$. Slices were continuously perfused with aCSF at a rate of $1 \mathrm{~mL}$ per min. Our aCSF contained (in $\mathrm{mM}$ ): $124 \mathrm{NaCl}$, $4.4 \mathrm{KCl}, 1.3 \mathrm{MgSO}_{4}, 1 \mathrm{NaH}_{2} \mathrm{PO}_{4}, 26.2 \mathrm{NaHCO}_{3}, 2.5 \mathrm{CaCl}_{2}$, and 10 glucose.

\section{Electrophysiology}

fEPSPs were recorded from the CA1 area by placing stimulating and recording electrodes in the stratum radiatum. Recording glass microelectrodes were filled with aCSF (resistance of 2-3 M $\Omega$ ), and bipolar nickel-chromium electrodes were used for stimulating the Schaffer collateral-commissural pathway. Two independent synaptic paths (S1 [homosynaptic pathway] and S2 [heterosynaptic pathway]) were stimulated; both converge onto the same population of CA1 pyramidal neurons. Both pathways were confirmed to be separate because they did not exhibit inter-pathway pairedpulse facilitation (Connor et al. 2011). fEPSPs were evoked at a stimulus intensity of $40 \%$ of their maximum amplitude, measured in $\mathrm{mV}$. fEPSPs were elicited at a test stimulation frequency of once per minute (0.08 msec pulse duration) by stimulating both pathways $200 \mathrm{msec}$ apart.

\section{Drugs}

Following 20 min of baseline recordings at test stimulation frequency, different protocols were administered involving drug application and/or high-frequency stimulation (one train of $100 \mathrm{~Hz}$ at $1 \mathrm{sec}$ train duration) to one pathway or both. This $100 \mathrm{~Hz}$ protocol was often paired with L-(-)- NE (+)-bitartrate salt monohydrate (NE) $(10 \mu \mathrm{M}$; Sigma) applied at S1. Induction of homosynaptic and heterosynaptic LTP by pairing one train of $100 \mathrm{~Hz}$ with ISO has been previously described (Gelinas and Nguyen 2005; Connor et al. 2011). In the present experiments, NE was applied $10 \mathrm{~min}$ before one train $(1 \mathrm{sec})$ of $100 \mathrm{~Hz}$ at S1, followed by an additional $5 \mathrm{~min}$ post-100 Hz. A PKA inhibitor, KT-5720 (KT) (1 $\mu \mathrm{M}$; Sigma), was dissolved in a stock concentration of $1 \mathrm{mM}$ in dimethyl sulfoxide (DMSO). PKA inhibitor fragment (PKI $1 \mu \mathrm{M} ; 14-22$ amide, myristoylated membrane-permeant from Calbiochem) was prepared as a $1 \mathrm{mM}$ stock solution in distilled water. KT was added $20 \mathrm{~min}$ prior to application of NE at S1; PKI was perfused for $20 \mathrm{~min}$ before NE application. The Epac inhibitors, ESI-09 (ESI; $\alpha$-[2-(3-chlorophenyl)hydrazinylidene]-5-(1,1-dimethylethyl)-b-oxo-3-isoxazolepropanenitrile) (10 $\mathrm{MM}$; Sigma) and BFA (10 $\mu \mathrm{M}$; Sigma), were dissolved in DMSO at $20 \mathrm{mM}$ and $10 \mathrm{mM}$, respectively. Each inhibitor remained present until 5 or 10 min after NE washout (35-45 min total drug application). Drugs which overlapped with one train (1 sec duration) of $100 \mathrm{~Hz}$ at S2 were applied starting at 20 
min before $100 \mathrm{~Hz}$ (with the exception of KT, which was perfused for $10 \mathrm{~min}$ prior to $100 \mathrm{~Hz}$ ) and continued for an additional $5 \mathrm{~min}$. Experiments were conducted under dimmed light conditions to minimize photolysis of light-sensitive drugs such as NE and some inhibitors. Drug experiments were interspersed with drugfree controls.

\section{Statistical analysis}

Data were analyzed offline using pCLAMP 10 software (Axon Instrument Inc.). Initial fEPSP slopes were measured as an index of synaptic strength (Johnston and $\mathrm{Wu}$ 1995). Slopes were averaged from 20 min of steady baseline recording (prior to $100 \mathrm{~Hz}$ ) to obtain a "baseline" mean value for each experiment. All subsequent slopes were expressed as percentages of these baseline mean slopes. Mean fEPSP slopes, measured 90 min after $100 \mathrm{~Hz}$ in S2, were used for inter-group comparisons of synaptic strength. Student's $t$-test was used for statistical comparisons of mean fEPSP slopes between two groups. One-way ANOVA and Tukey-Kramer post-hoc tests were used for comparing the significance between three or more groups (significance level of $P<0.05$ ). All values were standardized to the average baseline slope and reported as mean \pm SEM.

\section{Acknowledgments}

We thank Ms. J. Hoffman for her assistance with some of the slice experiments. This research was supported by a Discovery Grant (to P.V.N.) from the Natural Sciences and Engineering Research Council of Canada. N.J.B. received graduate support from this grant.

\section{References}

Abel T, Nguyen PV. 2008. Regulation of hippocampus-dependent memory by cyclic AMP-dependent protein kinase. Prog Brain Res 169: 97-115. doi:10.1016/S0079-6123(07)00006-4

Abel T, Nguyen PV, Barad M, Deuel TA, Kandel ER, Bourtchouladze R. 1997. Genetic demonstration of a role for PKA in the late phase of LTP and in hippocampus-based long-term memory. Cell 88: 615-626. doi:10.1016/ S0092-8674(00)81904-2

Aston-Jones G, Bloom FE. 1981. Norepinephrine containing locus coeruleus neurons in behaving rats exhibit pronounced responses to non-noxious environmental stimuli. J Neurosci 1: 887-900. doi:10.1523/ JNEUROSCI.01-08-00887.1981

Barco A, Alarcon JM, Kandel ER. 2002. Expression of constitutively active CREB protein facilitates the late phase of long-term potentiation by enhancing synaptic capture. Cell 108: 689-703. doi:10.1016/ S0092-8674(02)00657-8

Bliss TV, Collingridge GL. 1993. A synaptic model of memory: long-term potentiation in the hippocampus. Nature 361: 31-39. doi:10.1038/ $361031 \mathrm{a} 0$

Bliss TV, Lømo T. 1973. Long-lasting potentiation of synaptic transmission in the dentate area of the anaesthetized rabbit following stimulation of the perforant path. J Physiol 232: 331-356. doi:10.1113/jphysiol.1973. sp010273

Bourtchuladze R, Frenguelli B, Blendy J, Cioffi D, Schutz G, Silva AJ. 1994. Deficient long-term memory in mice with a targeted mutation of the cAMP-responsive element-binding protein. Cell 79: 59-68. doi:10.1016/ 0092-8674(94)90400-6

Connor SA, Wang YT, Nguyen PV. 2011. Activation of $\beta$-adrenergic receptors facilitates heterosynaptic translation-dependent long-term potentiation. J Physiol 589: 4321-4340. doi:10.1113/jphysiol.2011. 209379

Costa-Mattioli M, Sossin WS, Klann E, Sonenberg N. 2009. Translational control of long-lasting synaptic plasticity and memory. Neuron 61: 1026. doi:10.1016/j.neuron.2008.10.055

de Rooij J, Zwartkruis FJ, Verheijen MH, Cool RH, Nijman SM, Wittinghofer A, Bos JL. 1998. Epac is a Rap1 guanine-nucleotideexchange factor directly activated by cyclic AMP. Nature 396: 474-477. doi:10.1038/24884

Duffy SN, Craddock KJ, Abel T, Nguyen PV. 2001. Environmental enrichment modifies the PKA-dependence of hippocampal LTP and improves hippocampus-dependent memory. Learn Mem 8: 26-34. doi:10.1101/lm.36301

Eichenbaum H. 2000. A cortical-hippocampal system for declarative memory. Nat Rev Neurosci 1: 41-50. doi:10.1038/35036213
Frey U, Morris RG. 1997. Synaptic tagging and long-term potentiation. Nature 385: 533-536. doi:10.1038/385533a0

Frey U, Huang Y, Kandel E. 1993. Effects of cAMP simulate a late stage of LTP in hippocampal CA1 neurons. Science 260: 1661-1664. doi:10.1126/ science. 8389057

Gelinas JN, Nguyen PV. 2005. $\beta$-Adrenergic receptor activation facilitates induction of a protein synthesis-dependent late phase of long-term potentiation. J Neurosci 25: 3294-3303. doi:10.1523/JNEUROSCI.417504.2005

Gelinas JN, Banko JL, Hou L, Sonenberg N, Weeber EJ, Klann E, Nguyen PV. 2007. ERK and mTOR signaling couple $\beta$-adrenergic receptors to translation initiation machinery to gate induction of protein synthesis-dependent long-term potentiation. J Biol Chem 282: 2752727535. doi:10.1074/jbc.M701077200

Gelinas JN, Banko JL, Peters MM, Klann E, Weeber EJ, Nguyen PV. 2008. Activation of exchange protein activated by cyclic-AMP enhances long-lasting synaptic potentiation in the hippocampus. Learn Mem 15: 403-411. doi:10.1101/lm.830008

Grimes MT, Powell M, Gutierrez SM, Darby-King A, Harley CW, McLean JH. 2015. Epac activation initiates associative odor preference memories in the rat pup. Learn Mem 22: 74-82. doi:10.1101/lm.037101.114

Gutierrez-Castellanos N, Da Silva-Matos CM, Zhou K, Canto CB, Renner MC, Koene LMC, Ozyildirim O, Sprengel R, Kessels HW, De Zeeuw CI. 2017. Motor learning requires Purkinje cell synaptic potentiation through activation of AMPA receptor subunit GluA3. Neuron 93: 409-424. doi:10.1016/j.neuron.2016.11.046

Harley CW, Lalies MD, Nutt DJ. 1996. Estimating the synaptic concentration of norepinephrine in dentate gyrus which produces $\beta$-receptor mediated long-lasting potentiation in vivo using microdialysis and intracerebroventricular norepinephrine. Brain Res 710: 293-298. doi:10.1016/0006-8993(95)01443-8

Hillman KL, Doze VA, Porter JE. 2005. Functional characterization of the adrenergic receptor subtypes expressed by CA1 pyramidal cells in the rat hippocampus. J Pharmacol Exp Ther 314: 561-567. doi:10.1124/ jpet.105.084947

Hu H, Real E, Takamiya K, Kang M, Ledoux J, Huganir RL, Malinow R. 2007. Emotion enhances learning via norepinephrine regulation of AMPAreceptor trafficking. Cell 131: 160-173. doi:10.1016/j.cell.2007.09.017

Izquierdo I, Medina JH, Izquierdo LA, Barros DM, de Souza MM, Mello e Souza T. 1998. Short- and long-term memory are differentially regulated by monoaminergic systems in the rat brain. Neurobiol Learn Mem 69: 219-224. doi:10.1006/nlme.1998.3825

Ji J, Zhang X, Li B. 2003a. Deficient spatial memory induced by blockade of $\beta$-adrenoceptors in the hippocampal CA1 region. Behav Neurosci 117: 1378-1384. doi:10.1037/0735-7044.117.6.1378

Ji J, Wang X, Li B. 2003b. Deficit in long-term contextual fear memory induced by blockade of $\beta$-adrenoceptors in hippocampal CA1 region. Eur J Neurosci 17: 1947-1952. doi:10.1046/j.1460-9568.2003.02620.x

Johnston D, Wu SMS. 1995. Foundations of cellular neurophysiology. MIT Press, Cambridge, MA.

Katsuki H, Izumi Y, Zorumski CF. 1997. Noradrenergic regulation of synaptic plasticity in the hippocampal CA1 region. J Neurophysiol 77: 3013-3020. doi:10.1152/jn.1997.77.6.3013

Kawasaki H, Springett GM, Mochizuki N, Toki S, Nakaya M, Matsuda M, Housman DE, Graybiel AM. 1998. A family of cAMP-binding proteins that directly activate Rap1. Science 282: 2275-2279. doi:10.1126/ science.282.5397.2275

Kelleher R, Govindarajan A, Jung HY, Kang H, Tonegawa S. 2008. Mitogen-activated protein kinases in synaptic plasticity and memory. Cell 116: 501-523.

Klann E, Antion MD, Banko JL, Hou L. 2004. Synaptic plasticity and translation initiation. Learn Mem 11: 365-372. doi:10.1101/lm.79004

Krug M, Lössner B, Ott T. 1984. Anisomycin blocks the late phase of long-term potentiation in the dentate gyrus of freely moving rats. Brain Res Bull 13: 39-42. doi:10.1016/0361-9230(84)90005-4

Lemon N, Aydin-Abidin S, Funke K, Manahan-Vaughan D. 2009. Locus coeruleus activation facilitates memory encoding and induces hippocampal LTD that depends on $\beta$-adrenergic receptor activation. Cereb Cortex 19: 2827-2837. doi:10.1093/cercor/bhp065

Ma N, Abel T, Hernandez PJ. 2009. Epac enhances long-term memory formation independent of protein kinase A. Learn Mem 16: 367-370. doi:10.1101/lm.1231009

Maity S, Rah S, Sonenberg N, Gkogkas CG, Nguyen PV. 2015. Norepinephrine triggers metaplasticity of LTP by increasing translation of specific mRNAs. Learn Mem 22: 499-508. doi:10.1101/lm.039222.115

Maity S, Jarome TJ, Blair J, Lubin FD, Nguyen PV. 2016. Noradrenaline goes nuclear: epigenetic modifications during long-lasting synaptic potentiation triggered by activation of $\beta$-adrenergic receptors. J Physiol 594: 863-881. doi:10.1113/JP271432

Martin SJ, Grimwood PD, Morris RG. 2000. Synaptic plasticity and memory: an evaluation of the hypothesis. Annu Rev Neurosci 23: 649-711. doi:10.1146/annurev.neuro.23.1.649 
McPhee I, Gibson LC, Kewney J, Darroch C, Stevens PA, Spinks D, Cooreman A, Mackenzie SJ. 2005. Cyclic nucleotide signalling: a molecular approach to drug discovery for Alzheimer's disease. Biochem Soc Trans 33: 1330-1332. doi:10.1042/BST0331330

Moncada D. 2017. Evidence of VTA and LC control of protein synthesis required for the behavioural tagging process. Neurobiol Learn Mem 138: 226-237. doi:10.1016/j.nlm.2016.06.003

Moncada D, Ballarini F, Martinez MC, Frey JU, Viola H. 2011. Identification of transmitter systems and learning tag molecules involved in behavioural tagging during memory formation. Proc Natl Acad Sci 108: 12931-12936. doi:10.1073/pnas.1104495108

Murchison CF, Zhang X, Zhang W, Ouyang M, Lee A, Thomas SA. 2004. A distinct role for norepinephrine in memory retrieval. Cell 117: 131-143. doi:10.1016/S0092-8674(04)00259-4

Navakkode S, Sajikumar S, Frey JU. 2004. The type-IV-specific phosphodiesterase inhibitor rolipram and its effect on hippocampal LTP and synaptic tagging. J Neurosci 24: 7740-7744. doi:10.1523/ JNEUROSCI.1796-04.2004

Nayak A, Zastrow DJ, Lickteig R, Zahniser NR, Browning MD. 1998. Maintenance of late-phase LTP is accompanied by PKA-dependent increase in AMPA receptor synthesis. Nature 394: 680-683. doi:10.1038/ 29305

Neugebauer F, Korz V, Frey JU. 2009. Modulation of extracellular monoamine transmitter concentrations in the hippocampus after weak and strong tetanisation of the perforant path in freely moving rats. Brain Res 1273: 29-38. doi:10.1016/j.brainres.2009.03.055

Nguyen PV, Gelinas JN. 2018. Noradrenergic gating of long-lasting synaptic potentiation in the hippocampus: from neurobiology to translational biomedicine. J Neurogenet 32: 171-182. doi:10.1080/ 01677063.2018.1497630

Nguyen P, Woo N. 2003. Regulation of hippocampal synaptic plasticity by cyclic AMP-dependent protein kinases. Prog Neurobiol 71: 401-437. doi:10.1016/j.pneurobio.2003.12.003

Nie T, McDonough CB, Huang T, Nguyen PV, Abel T. 2007. Genetic disruption of protein kinase A anchoring reveals a role for compartmentalized kinase signaling in $\theta$-burst long-term potentiation and spatial memory. J Neurosci 27: 10278-10288. doi:10.1523/ JNEUROSCI.1602-07.2007

Nijholt IM, Dolga AM, Ostroveanu A, Luiten PG, Schmidt M, Eisel UL. 2008. Neuronal AKAP150 coordinates PKA and Epac-mediated PKB/Akt phosphorylation. Cell Signal 20: 1715-1724. doi:10.1016/j. cellsig.2008.05.001

O’Dell TJ, Connor SA, Guglietta R, Nguyen PV. 2015. $\beta$-Adrenergic receptor signaling and modulation of long-term potentiation in the mammalian hippocampus. Learn Mem 22: 461-471. doi:10.1101/lm.031088.113

Ostroveanu A, van der Zee EA, Eisel UL, Schmidt M, Nijholt IM. 2010. Exchange protein activated by cyclic AMP 2 (Epac2) plays a specific and time-limited role in memory retrieval. Hippocampus 20: 1018-1026. doi:10.1002/hipo. 20700

Ouyang M, Zhang L, Zhu JJ, Schwede F, Thomas SA. 2008. Epac signalling is required for hippocampus-dependent memory retrieval. Proc Natl Acad Sci 105: 11993-11997. doi:10.1073/pnas.0804172105

Park AJ, Havekes R, Choi JH, Luczak V, Nie T, Huang T, Abel T. 2014. A presynaptic role for PKA in synaptic tagging and memory. Neurobiol Learn Mem 114: 101-112. doi:10.1016/j.nlm.2014.05.005

Qian H, Matt L, Zhang M, Nguyen M, Patriarchi T, Koval OM, Anderson ME, He K, Lee HY, Hell JW. 2012. $\beta 2$-adrenergic receptor supports prolonged $\theta$ tetanus-induced LTP. J Neurophysiol 107: 2703-2712. doi:10.1152/ jn.00374.2011
Sajikumar S, Frey JU. 2004. Late associativity, synaptic tagging, and the role of dopamine during LTP and LTD. Neurobiol Learn Mem 82: 12-25. doi:10.1016/j.nlm.2004.03.003

Sajikumar S, Navakkode S, Frey JU. 2007. Identification of compartmentand process-specific molecules required for "synaptic tagging" during long-term potentiation and long-term depression in hippocampal CA1. J Neurosci 27: 5068-5080. doi:10.1523/JNEUROSCI.4940-06.2007

Sara SJ, Segal M. 1991. Plasticity of sensory responses of locus coeruleus neurons in the behaving rat: implications for cognition. Prog Brain Res 88: 571-585. doi:10.1016/S0079-6123(08)63835-2

Sara SJ, Roullet P, Przybyslawski J. 1999. Consolidation of memory for odor-reward association: $\beta$-adrenergic receptor involvement in the late phase. Learn Mem 6: 88-96.

Scoville WB, Milner B. 1957. Loss of recent memory after bilateral hippocampal lesions. J Neurol Neurosurg Psychiatry 20: 11-21. doi:10.1136/jnnp.20.1.11

Stanton P, Sarvey J. 1984. Blockade of long-term potentiation in rat hippocampal CA1 region by inhibitors of protein synthesis. J Neurosci 4: 3080-3088. doi:10.1523/JNEUROSCI.04-12-03080.1984

Straube T, Korz V, Balschun D, Frey JU. 2003. Requirement of $\beta$-adrenergic receptor activation and protein synthesis for LTP-reinforcement by novelty in rat dentate gyrus. J Physiol 552: 953-960. doi:10.1113/ jphysiol.2003.049452

Thomas MJ, Moody TD, Makhinson M, O'Dell TJ. 1996. Activity-dependent $\beta$-adrenergic modulation of low frequency stimulation induced LTP in the hippocampal CA1 region. Neuron 17: 475-482. doi:10.1016/ S0896-6273(00)80179-8

Wan X, Torregrossa MM, Sanchez H, Nairn AC, Taylor JR. 2014. Activation of exchange protein activated by cAMP in the rat basolateral amygdala impairs reconsolidation of a memory associated with self-administered cocaine. PLoS One 9: e107359. doi:10.1371/journal.pone.0107359

Whitlock JR, Heynen AJ, Schuler MG, Bear MF. 2006. Learning induces long-term potentiation in the hippocampus. Science 313: 1093-1097. doi:10.1126/science.1128134

Winder DG, Martin KC, Muzzio IA, Rohrer D, Chruscinski A, Kobilka B, Kandel ER. 1999. ERK plays a regulatory role in induction of LTP by $\theta$ frequency stimulation and its modulation by $\beta$-adrenergic receptors. Neuron 24: 715-726. doi:10.1016/S0896-6273(00)81124-1

Woo NH, Duffy SN, Abel T, Nguyen PV. 2003. Temporal spacing of synaptic stimulation critically modulates the dependence of LTP on cyclic AMP-dependent protein kinase. Hippocampus 13: 293-300. doi:10.1002/hipo.10086

Yang Y, Shu X, Liu D, Shang Y, Wu Y, Pei L, Xu X, Tian Q, Zhang J, Qian K, et al. 2012. EPAC null mutation impairs learning and social interactions via aberrant regulation of miR-124 and Zif268 translation. Neuron 73: 774-788. doi:10.1016/j.neuron.2012.02.003

Young JZ, Isiegas C, Abel T, Nguyen PV. 2006. Metaplasticity of the late-phase of long-term potentiation: a critical role for protein kinase A in synaptic tagging. Eur J Neurosci 23: 1784-1794. doi:10.1111/ j.1460-9568.2006.04707.x

Zola-Morgan S, Squire LR, Amaral DG. 1986. Human amnesia and the medial temporal region: enduring memory impairment following a bilateral lesion limited to field CA1 of the hippocampus. J Neurosci 6: 2950-2967. doi:10.1523/JNEUROSCI.06-10-02950.1986

Received October 31, 2018; accepted in revised form November 30, 2018. 


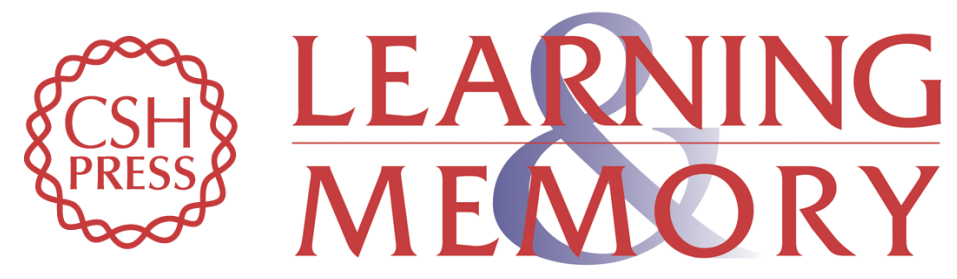

\section{Noradrenergic stabilization of heterosynaptic LTP requires activation of Epac in the hippocampus}

Nathan J. Brandwein and Peter V. Nguyen

Learn. Mem. 2019, 26:

Access the most recent version at doi:10.1101/Im.048660.118

\begin{aligned} & \hline References $\begin{array}{l}\text { This article cites } 66 \text { articles, } 24 \text { of which can be accessed free at: } \\ \text { http://learnmem.cshlp.org/content/26/2/31.full.html\#ref-list-1 }\end{array} \\ & \begin{aligned} \text { Creative } \\ \text { Commons } \\ \text { License }\end{aligned} \begin{array}{l}\text { This article is distributed exclusively by Cold Spring Harbor Laboratory Press for the } \\ \text { first } 12 \text { months after the full-issue publication date (see } \\ \text { http://learnmem.cshlp.org/site/misc/terms.xhtml). After } 12 \text { months, it is available under } \\ \text { a Creative Commons License (Attribution-NonCommercial } 4.0 \text { International), as } \\ \text { described at http://creativecommons.org/licenses/by-nc/4.0/. }\end{array} \\ & \begin{array}{c}\text { Receive free email alerts when new articles cite this article - sign up in the box at the } \\ \text { top right corner of the article or click here. }\end{array} \\ & \begin{array}{c}\text { Service } \\ \text { terting }\end{array}\end{aligned}$ 